\title{
¿Cómo se controla la infracción constitucional originada en el no sometimiento de un tratado a la aprobación del Congreso Nacional?
}

\author{
Miriam Lorena Henríquez Viñas*
}

\begin{abstract}
RESUMEN
El presente trabajo analiza el caso en que el Presidente de la República califica un tratado como uno de aquellos que no versa sobre materias propias de ley, en circunstancias que sí las trata, y lo tramita en el ejercicio de su potestad reglamentaria autónoma y no lo somete a la aprobación del Congreso Nacional. Así, busca establecer cómo se controla y corrige dicha infracción constitucional por el Tribunal Constitucional y la Contraloría General de la República.
\end{abstract}

Tratados internacionales - potestad reglamentaria autónoma control de constitucionalidad

\section{How the constitutional violation originated in no submission of a treaty to the approval of the Congress is controlled?}

\begin{abstract}
This paper analyzes the case where the President calls a treaty as one of those who is not about legal reserve, in circumstances which deals with such matters, and processed in the exercise of his regulatory authority and not submits to the approval of Congress. So, searchs to establish how controls and corrects this constitutional by the Constitutional Court and the Comptroller of the Republic.
\end{abstract}

International treaties - autonomous regulatory authority control of constitutionality

\footnotetext{
${ }^{1}$ Abogado, Universidad Nacional del Comahue, Argentina. Magíster en Derecho Público con mención en Derecho Constitucional, Pontificia Universidad Católica de Chile. Doctor en Ciencias Jurídicas, Universidad de Santiago de Compostela, España. Profesora Derecho Constitucional Universidad Alberto Hurtado.Email: mhenriqu@uahurtado.cl-miriamhenriquez@yahoo.es.

Artículo recibido el 30 de marzo de 2015 y aceptado para su publicación el 21 de enero de 2016.
} 


\section{INTRODUCCIÓN}

$\mathrm{E}$ 1 Derecho Internacional no establece un procedimiento único para la celebración de tratados. Los Estados que intentan celebrar un tratado pueden convenir cualquier procedimiento o forma. En particular, pueden acordar ceñirse a un procedimiento formal o a uno simplificado ${ }^{1}$.

La Constitución Política de la República de Chile distingue en el proceso de formalización de un tratado varias etapas: la negociación y acuerdo, la aprobación y la ratificación, prestando más atención a la fase de ratificación por el Presidente de la República y a la previa aprobación por el Congreso Nacional, de conformidad con los artículos $32 \mathrm{~N}^{\circ} 15$ y $54 \mathrm{~N}^{\circ} 1$, respectivamente. Corresponde adelantar que la Constitución dispone, en el artículo $54 \mathrm{~N}^{\circ} 1$ inciso cuarto, que solo los tratados que versan respecto de materias propias de ley deberán sujetarse por el Presidente de la República a la aprobación del Congreso Nacional.

En tal contexto, el presente trabajo pretende analizar el caso en que el Presidente de la República califica un tratado como uno de aquellos que no versa acerca de materias propias de ley, en circunstancias que sí trata dichas materias, y lo tramita en el ejercicio de su potestad reglamentaria autónoma y no lo somete a la aprobación del Congreso Nacional. Este supuesto se plantea la siguiente interrogante: ¿Cómo se controla y corrige dicha infracción constitucional? Cuando afirmo "infracción constitucional” me refiero al incumplimiento de las normas procedimentales fijadas por la Constitución para la generación de una norma o cuando existen vicios de competencia ${ }^{2}$.

La importancia del tema propuesto radica en que cada vez son más frecuentes los tratados que deben celebrarse de forma simplificada debido a la agilidad que demandan las relaciones internacionales, siendo necesario conocer el control a que quedan sujetos los tratados celebrados sin la intervención del Congreso Nacional, quien mediante la

${ }^{1}$ El procedimiento formal o solemne de celebración de tratados comprende usualmente las etapas de negociación, la adopción del texto, la firma y la manifestación del consentimiento en obligarse por el tratado que se expresa comúnmente mediante la ratificación o la adhesión. Tanto la ratificación como la adhesión pueden ser precedidas por la aprobación parlamentaria del tratado si el respectivo Derecho interno así lo requiere. Finalmente, se prevé el canje o el depósito de los instrumentos de ratificación o de adhesión. Sin embargo, los Estados pueden convenir celebrar un tratado por medio de un procedimiento simplificado en el que se omiten algunas de las etapas señaladas del procedimiento formal. Los procedimientos simplificados más comunes son aquellos que una vez negociados y establecidos el texto del tratado, el consentimiento de los Estados en obligarse se manifiesta mediante la firma de los representantes de los Estados o el canje de los instrumentos que constituyen el tratado. No requieren entonces de los trámites de la aprobación por el Congreso ni la ratificación. Benadava, S., Derecho Internacional Público, LexisNexis (8va edición), Santiago, 2004, p. 42 y ss.

${ }^{2}$ Miriam Henríquez distingue a propósito de los conflictos normativos las incompatibilidades formales y materiales, llamando a las primeras "infracciones". Henríquez, M, "Los jueces y la resolución de antinomias desde la perspectiva de las fuentes del Derecho constitucional chileno", en Revista Estudios Constitucionales, Año $11 \mathrm{~N}^{\circ} 1,2013$, p. 461. En un sentido coincidente, Carla Huerta expone que existen casos en que el conflicto deriva de un problema formal y la norma "imperfecta” puede ser derogada o declarada inválida, estos casos son denominados por ella: “infracción”. Huerta, C., Conflictos normativos, Instituto de Investigaciones Jurídicas UNAM, México, 2007, p. 52. 
aprobación realiza un control político del accionar del Presidente de la República en materia de asuntos exteriores.

A partir del caso propuesto se generan varias preguntas conexas: a) ¿Qué sucede cuando el Presidente de la República estima que un tratado internacional no versa sobre materias propias de ley y lo aprueba en el ejercicio de su potestad reglamentaria autónoma, en circunstancias que el tratado sí regula materia legal?; b) ¿Procede requerir el control previo de constitucionalidad al Tribunal Constitucional a pesar que la Constitución establece como oportunidad para ejercer dicho control que el tratado se encuentre "sometido a la aprobación del Congreso"?; c) Si el Tribunal Constitucional no tiene competencia para ejercer dicho control ¿Es competente la Contraloría General de la República para detectar la infracción cuando ejerce el control previo de juridicidad del decreto supremo por el cual se aprobó el tratado?; d) ¿Podría un cuarto de los diputados en ejercicio requerir al Tribunal Constitucional para que ejerza un control represivo del decreto supremo aprobatorio del tratado de conformidad con el artículo $93 \mathrm{~N}^{\circ} 16$ ?

Las interrogantes propuestas guiarán el desarrollo de este artículo, el que tendrá el siguiente orden de exposición: a) En primer lugar examinaré la atribución del Presidente de la República para someter los tratados que él está gestionando a la aprobación del Congreso y la finalidad de dicha intervención parlamentaria; b) Luego revisaré si el Tribunal Constitucional está facultado para ejercer el control previo de constitucionalidad del tratado tramitado por el Presidente de la República en el ejercicio de su potestad reglamentaria autónoma; c) Una vez identificada la competencia o no del Tribunal Constitucional, procederé a analizar la competencia de la Contraloría General de la República para detectar la infracción constitucional que se configura cuando el Presidente de la República no somete el tratado a la aprobación del Congreso, debiendo hacerlo; d) Finalmente me referiré a la procedencia del control represivo por el Tribunal Constitucional para declarar la inconstitucionalidad de un decreto aprobatorio del tratado en el supuesto de exceso de la potestad reglamentaria autónoma; y e) Por último expondré las correspondientes conclusiones.

El estudio trazado lo realizaré a partir de la revisión de la doctrina constitucional, eventualmente internacional, con referencias a la jurisprudencia constitucional y administrativa respecto de la materia. Corresponde señalar que la doctrina constitucional ha prestado poca atención al asunto planteado en este trabajo, siendo por tanto escasos los recursos bibliográficos disponibles. Lo anterior pretendo compensarlo con referencia a la jurisprudencia administrativa emanada de la Contraloría General de la República, quien ha resuelto varios casos relativos a la temática expuesta.

\section{LA ATRIBUCIÓN PRESIDENCIAL PARA SOMETER LOS TRATADOS A LA APROBACIÓN DEL CONGRESO NACIONAL}

El Presidente de la República tiene entre sus atribuciones gubernativas aquellas referidas a las relaciones internacionales. Por esto, y en primer lugar, el artículo 24 de la Constitución dispone que el Presidente de la República, como Jefe de Estado, le 
corresponde la función de representarlo tanto en el orden interno como externo. Como también es Jefe de Gobierno le compete conducir las relaciones internacionales y participar en la celebración de tratados, todo de conformidad con el artículo $32 \mathrm{~N}^{0} 15$ que expresa como atribución del Presidente de la República la de conducir las relaciones políticas con las potencias extranjeras y organismos internacionales, llevar a cabo las negociaciones, concluir, firmar y ratificar los tratados, los que deberán ser sometidos a la aprobación del Congreso, conforme a lo prescrito en el artículo 54 N $\mathrm{N}^{\circ} 1$.

Como se observa el Presidente de la República cuenta con la iniciativa exclusiva para negociar los tratados, concluirlos, firmarlos y ratificarlos con una acentuada discrecionalidad, tanto así que la Constitución expresa que el Presidente ratificará un tratado "si lo estima conveniente para los intereses del país".

A su vez, el Presidente de la República es quien somete el tratado a la aprobación del Congreso Nacional, decisión que adoptará a base de la coyuntura política ${ }^{3}$, salvo que el tratado verse acerca de materias propias de ley, en cuyo caso deberá hacerlo ${ }^{4}$. Los argumentos que sirven de apoyo a lo afirmado surgen del propio texto constitucional. En primer lugar, el actual artículo $54 \mathrm{~N}^{\circ} 1$ inciso 4 expresa que los tratados internacionales que versen pertinente a materias propias de ley quedarán sujetos a ese trámite: "Las medidas que el Presidente de la República adopte o los acuerdos que celebre para el cumplimiento de un tratado en vigor no requerirán de nueva aprobación del Congreso, a menos que se trate de materias propias de ley". A su vez la Constitución señala, en forma negativa: "No requerirán de aprobación del Congreso los tratados celebrados por el Presidente de la República en el ejercicio de su potestad reglamentaria”.

De esta forma, del propio texto se desprende que es imperativo para el Presidente de la República someter un tratado internacional a la aprobación del Congreso cuando el mismo trata materias del dominio legal. Sin embargo, si el tratado es ajeno a las materias comprendidas en la reserva legal, el Presidente podrá "celebrarlo en el ejercicio de su potestad reglamentaria” y no será obligatorio someterlo a dicha aprobación.

Dispuesto así el diseño constitucional, podría interpretarse que la exclusión del control parlamentario obedece más a una razón material que a la urgencia de su entrada en vigor o a la necesidad de una forma simplificada para su conclusión.

Efectivamente la Constitución relaciona los posibles contenidos del tratado con las materias del dominio legal, reiterando la distribución prevista para el plano interno entre materias reservadas a ley y a la potestad reglamentaria autónoma ${ }^{5}$. En el mismo sentido

${ }^{3}$ Henríquez, M., “Atribución exclusiva del Congreso: aprobación de tratados internacionales”, en Revista de Derecho Público, 65, 2003, p. 261.

${ }^{4}$ Para determinar si un tratado versa sobre materia propia de ley habrá de estarse a lo dispuesto en el artículo 63 de la Constitución. Ver Fernández, M., "Visión prospectiva en relación con la regulación constitucional de los tratados internacionales", en Revista Ius et Praxis, 9 N ${ }^{\circ}$ 1, 2003, p. 506.

${ }^{5}$ En un sentido diverso, Rodrigo Correa plantea la posibilidad que en materia de tratados internacionales el Presidente de la República ostente una potestad presidencial autónoma, aunque no necesariamente análoga a su potestad reglamentaria autónoma en el orden interno. Correa, R., "Los acuerdos en forma simplificada en una Constitución democrática: comentario a fallo del Tribunal Constitucional”, en Estudios Públicos, 75, 1999, p. 73. 
opina Eduardo Aldunate, quien expresa: "Nuestra Constitución asimila el objeto de un tratado a las materias propias de ley. Ello resulta claro cuando se aprecia, en primer lugar, la referencia a los tratados que versen sobre materias propias de las leyes orgánicas constitucionales, en el art. 93. i. I $\mathrm{N}^{0} 1$, y la alusión contenida en el inciso IV del art. $54 \mathrm{~N}^{\circ} 1$, en relación a que el Presidente no requerirá de una nueva aprobación del Congreso para celebrar acuerdos para el cumplimiento de un tratado en vigor 'a menos que se trate de materias propias de ley'. Por último, la referencia en ese mismo inciso a los tratados celebrados por el Presidente de la República 'en ejercicio de su potestad reglamentaria' confirma el trato que da la Constitución a los tratados en lo que respecta a su objeto. El art. 54 i. I, además, somete la aprobación de un tratado a los quórum que correspondan de acuerdo al art. 66 CPR". 6

Lo señalado es por demás curioso por cuanto no siempre los contenidos de un tratado serán "encuadrables" en las materias que la Constitución estableció como propias del dominio legal y porque esta solución no atiende a la distinta naturaleza, tramitación y efectos de los tratados y la ley. Aunque sea una afirmación evidente: los tratados internacionales son fuentes del Derecho distintos que la ley, aun cuando la Constitución trate de asimilarlos parcialmente.

Por otro lado, y también desde la perspectiva de la construcción constitucional, es inadecuado afirmar que los tratados los aprueba el Presidente de la República en el ejercicio de su potestad reglamentaria cuando no tratan materias de ley, ya que no es posible que un tratado, en sí mismo un acto bilateral, sea aprobado por medio del ejercicio de una potestad unilateral de un órgano del Estado ${ }^{7}$. En puridad el Presidente de la República "aprueba" el tratado mediante la dictación de un decreto supremo que, al no tratar sobre materia legal, es calificado por la Constitución como emanado de la potestad reglamentaria autónoma. Esta distinción es relevante a los fines del control de la infracción constitucional, pues, en definitiva, no se estará controlando el contenido

${ }^{6}$ Coincide con esta afirmación Aldunate, E., "La posición de los tratados internacionales en el sistema de fuentes del ordenamiento jurídico chileno a la luz del derecho positivo", en Revista Ius et Praxis, Año 16, $\mathrm{N}^{\circ} 12,2010$, pp. 192 y 193.

${ }^{7}$ Comparto la afirmación de Eduardo Aldunate quien expresa: "Se confirma esta errónea apreciación de la naturaleza y función de los tratados cuando la Constitución, tras la reforma del 2005, habla de tratados celebrados en ejercicio de la potestad reglamentaria. Lo que se quiere decir resulta bastante claro; en el concepto que se viene discutiendo, correspondería a tratados que no tienen por objeto materias propias de ley. Sin embargo, el uso de la expresión deja en evidencia el error conceptual; la potestad reglamentaria es justamente la potestad normativa unilateral que tiene la autoridad como autoridad ejecutiva. No existe posibilidad de que, en ejercicio de esa potestad, la autoridad "celebre tratados", ya que los tratados, si bien en nuestro país son negociados, suscritos y ratificados por el Presidente, son siempre celebrados en virtud de la capacidad que se reconoce al Estado como sujeto de derecho internacional para contraer obligaciones internacionales. Este ius tractactum, aun cuando radicado en el ordenamiento nacional en el Presidente de la República, no es parte ni manifestación de su potestad reglamentaria, con independencia de la materia sobre la que recaiga y, además, tiene siempre la naturaleza de una facultad para celebrar pactos -y no la de una potestad unilateral-". Aldunate, E., "La posición de los tratados internacionales en el sistema de fuentes del ordenamiento jurídico chileno a la luz del derecho positivo", en Revista Ius et Praxis, Año 16, $\mathrm{N}^{\circ} 12,2010$, pp. 194-195. 
del tratado sino el procedimiento de su celebración, uno de cuyas etapas se formaliza mediante la dictación de un decreto autónomo, siendo este el objeto controlado y no el contenido del tratado 8 .

Continuando con el análisis, previo a la reforma constitucional de 2005, no hubo acuerdo en la doctrina nacional ${ }^{9}$, en la jurisprudencia del Tribunal Constitucional y de la Contraloría General de la República ${ }^{10}$, ni en la práctica de la Cancillería ${ }^{11}$, respecto de cuáles tratados estaban exentos del control parlamentario. Sin embargo, las diferencias

${ }^{8}$ Así lo ha entendido la Contraloría General de la República, quien en su jurisprudencia administrativa ha afirmado que el objeto del control es el acto administrativo que aprueba el tratado. En sus términos: "En consecuencia cabe concluir que en mérito de los antecedentes que se han tenido a la vista el acto administrativo que aprueba la modificación del acuerdo de cooperación antes referido, se encuentra afecto a control previo de juridicidad”. Contraloría General de la República. Dictamen No 48.450. 2 de septiembre de 2009.

${ }^{9}$ Emilio Pfeffer distinguía: "Existen tratados internacionales que no requieren ser sometidos a la consideración y aprobación del Congreso. Se exceptúan, por ejemplo, aquellos pactados: 1. En cumplimiento de una ley. En este caso, en razón de que el Congreso ya dio su aprobación a la ley, correspondiéndole constitucionalmente al Presidente de la República su ejecución; 2. Los que complementen un tratado ya en vigencia. Como es el caso de los llamados tratados marco, que trazan las líneas directrices y fijan las pautas generales dentro de las cuales debe encuadrarse el ejercicio de determinadas actividades que se regularán por acuerdos especiales. Caso en el que se estima que habiéndose prestado la aprobación al tratado general, implícitamente se confirió la aprobación para suscribir los acuerdos destinados a ejecutar o cumplir lo dispuesto en el acuerdo anterior. Con una única excepción "si su contenido se refiere a materias de ley, requerirá autorización legislativa, y necesariamente debe someterse a consideración del Congreso"; y 3. Los acordados en virtud de las facultades exclusivas del Presidente de la República. En este caso la firma y ratificación del tratado internacional corresponde al ejercicio de las facultades constitucionales y legales, privativas del Jefe de Estado, cuyo ejercicio no quita ni agrega nada a sus atribuciones que son preexistentes. Simplemente, se limitan a reafirmarlas y, por lo mismo, no requieren de aprobación del Congreso, ni para su entrada en vigor, ni para su cumplimiento". Pfeffer, E., "Constitución Política de la República y Tratados Internacionales", Revista Ius et Praxis, Vol. 2 No 2, 1997, pp. 66 y 67.

Hugo Llanos afirmaba que no requieren de aprobación del Congreso Nacional los tratados: a) pactados en cumplimiento de una ley; b) pactados en cumplimiento de un tratado vigente; y c) tratados pactados en uso de las facultades reglamentarias del Presidente de la República. Llanos, H, "Los tratados y la reforma constitucional”, en La Constitución reformada de 2005 (Nogueira, Coordinador), Librotecnia, 2005, pp. 347-351.

${ }^{10}$ La jurisprudencia administrativa de la Contraloría General de la República, previa a la reforma constitucional de 2005, contenida en los dictámenes números 44.263 de 1988,1.150 de 1993, 1.842 de 1993 , 30.709 de 1993, 33.812 de 1998, 13.386 de 1999, 38.950 de 1999, 4.720 de 2000 planteaba, en líneas generales, como necesario para celebrar acuerdo en el uso de la potestad reglamentaria presidencial de una ley habilitante o un tratado vigente. Para un completo análisis de los dictámenes referidos ver Rodríguez, B., Potestad reglamentaria del Presidente de la República en materia de tratados internacionales. Memoria para optar al grado de Licenciado en Ciencias Jurídicas y Sociales, Universidad de Chile, 2010, pp. 103-113.

${ }^{11}$ La doctrina de la Cancillería sostenida desde antaño, incluso bajo la vigencia de la Constitución de 1925, expuso tres casos en que no era necesaria la aprobación de los tratados por el Congreso: a) tratados concluidos en cumplimiento de una ley, b) tratados concluidos en cumplimiento de otro tratado, c) tratados celebrados por el Presidente de la República en el uso de su potestad reglamentaria. A mayor abundamiento explica Llanos Mansilla: "Desde antiguo se sostiene por la Cancillería chilena que, de acuerdo al ordenamiento jurídico vigente, no todos los tratados necesitaban someterse a los trámites de aprobación previa del Congreso ni de ratificación. De acuerdo a este criterio, la ratificación procedía únicamente cuando la aprobación legislativa se hacía necesaria, y esta lo era solo respecto de ciertos tratados. En concordancia con lo anterior, se sostenía que no había obligación de someter a la aprobación del Congreso Nacional aquellos acuerdos internacionales que caían dentro de las facultades administrativas corrientes del gobierno, ni 
de criterio fueron zanjadas - de alguna forma- con la reforma constitucional de 2005 que distinguió expresamente en el mencionado artículo $54 \mathrm{~N}^{\circ} 1$ inciso cuarto aquellos tratados que debían quedar sometidos a la aprobación del Congreso Nacional de aquellos que quedan excluidos de dicho trámite.

Así, están exceptuados de tal trámite los siguientes tratados: a) aquellos pactados para el cumplimiento de un tratado en vigor, para los fines de su ejecución interna, salvo que las materias del nuevo acuerdo excedan al primero o que traten materias propias de ley; y b) aquellos aprobados por el Presidente de la República en el ejercicio de su potestad reglamentaria autónoma, prevista en el artículo $32 \mathrm{~N}^{\circ} 6$, es decir, cuando las materias del tratado no correspondan al dominio legal.

En ambos casos, la aprobación se formaliza mediante la dictación de un decreto supremo firmado por el Presidente de la República, con la firma del Ministro de Relaciones Exteriores o por orden del Presidente emitido por este último Ministerio. Corresponde aclarar que, a mi juicio y reiterando, la aprobación se formaliza mediante la dictación de un decreto supremo, lo que no transforma al tratado internacional en tal fuente. Corrobora esta última afirmación lo explicado por Eduardo Cordero acerca de la distinción entre la forma y el contenido de las decisiones administrativas: "Es muy habitual que se le atribuya cierta sustantividad a un acto, a pesar que sus elementos constitutivos son esencialmente formales, independiente al contenido del mismo. Esto ocurre habitualmente con los decretos supremos y las resoluciones. Ambas habitualmente se presentan como tipos de normas o actos administrativos, siendo que solo constituyen la forma que adopta la expresión de voluntad de determinadas autoridades en el ámbito jurídico para ejercer sus competencias, lo cual es independiente al contenido del mismo" 12 .

Por su parte, la principal atribución del Congreso Nacional: aprobar o desechar los tratados internacionales que le someta el Presidente de la República antes de su ratificación, satisface la necesidad de control que tiene el Congreso Nacional sobre el gobierno respecto de su función exterior, cumpliendo así una función política de democratización de las relaciones internacionales ${ }^{13}$.

En este rol, el Congreso debe limitarse a aprobar o desechar el tratado, no pudiendo formular enmiendas, adiciones o correcciones. En ambos casos -aprobación o rechazo- la decisión debe adoptarse con las mayorías previstas por el artículo 66, es decir, según sea la materia de ley de que se trate. En cuanto al procedimiento que debe seguir el Congreso Nacional, la Constitución explícitamente señala que la aprobación de los tratados deberá seguir en lo pertinente los trámites previstos para la formación de la ley.

tampoco procedía respecto de ellos, el trámite de la ratificación". Llanos, H., "Vigencia de los tratados en Chile", en Revista Chilena de Derecho, No 4, 1977, p. 183.

${ }^{12}$ Cordero, E., "Las normas administrativas y el sistema de fuentes", en Revista de Derecho Universidad Católica del Norte, Año 17 No 1, 2010, p. 23.

${ }^{13} \mathrm{La}$ función democratizadora es explicada por Espada Ramos diciendo que los representantes del pueblo van a mediatizar las iniciativas del gobierno, evitando conflictos en una fase previa a la manifestación del consentimiento estatal en obligarse y dando seguridad y eficacia a los compromisos que definitivamente asuma el Estado. Espada, M., "El control interno de los tratados internacionales", en Revista Española de Derecho Internacional, $\mathrm{N}^{\mathrm{os}} 1$ y 3, 1980, p. 14. 


\section{Facultades del Tribunal Constitucional para ejercer control PREVIO DE CONSTITUCIONALIDAD DE UN TRATADO APROBADO POR el Presidente de la República en el ejercicio de su potestad REGLAMENTARIA AUTÓNOMA}

El control previo de constitucionalidad de los tratados es una función necesaria para prevenir la infracción o contradicción de las normas contenidas en un tratado respecto de las normas constitucionales y para eludir los efectos negativos que podría acarrear el control represivo de constitucionalidad para la estabilidad de los compromisos internacionales y la seriedad del Estado en el ámbito internacional ${ }^{14}$.

Corresponde aclarar que el fin del control previo ejercido por el Tribunal Constitucional no es eliminar del ordenamiento jurídico una antinomia. Lo que se busca con el ejercicio de este control es justamente evitar que se produzca tal conflicto, toda vez que el objeto del control es un tratado internacional aún no vigente en el Derecho interno. De modo que lo se comprobará es una eventual inconstitucionalidad, formal en este caso, de un "proyecto de tratado" que si se incorpora al ordenamiento jurídico interno será inconstitucional ${ }^{15}$.

La inconstitucionalidad por vicios de procedimiento surge de diversas circunstancias, por ejemplo: a) El no sometimiento de un tratado cuyas normas versan acerca de materias propias de ley al control parlamentario, previo a la ratificación; b) La aprobación del tratado por un procedimiento distinto, en lo pertinente, al previsto para la tramitación de la ley; c) La aprobación del tratado con un quórum distinto al exigido por el artículo 66 de la Constitución según la materia respecto de la que versa el tratado. Como adelanté, el objetivo de este análisis se centra solo en la primera hipótesis.

La Constitución faculta al Tribunal Constitucional a ejercer un control previo, abstracto y obligatorio de los tratados internacionales cuando sus normas versen sobre materias de ley orgánica constitucional en el artículo $93 \mathrm{~N}^{\circ} 1$, que expresa: "Ejercer el control de constitucionalidad de las leyes que interpreten algún precepto de la Constitución, de las leyes orgánicas constitucionales y de las normas de un tratado que versen sobre materias propias de estas últimas, antes de su promulgación"; y a ejercer un control previo, abstracto y facultativo de los tratados internacionales en el número 3 del mismo numeral, que señala: "Resolver las cuestiones sobre constitucionalidad que se susciten durante la tramitación de los proyectos de ley o de reforma constitucional y de los tratados sometidos a la aprobación del Congreso". En ambos casos la Constitución supone que la intervención del Tribunal Constitucional tiene como presupuesto y oportunidad que el tratado se encuentre sometido a la aprobación del Congreso Nacional,

${ }^{14}$ En un sentido coincidente Nogueira, H., "Reforma constitucional de 2005 y control de constitucionalidad de tratados internacionales", en Revista Estudios Constitucionales, Año 5 N N $^{\circ}, 2007$, pp. 70 y ss. Además, Henríquez, M., "Improcedencia del control represivo de constitucionalidad de tratados internacionales”, en Revista Estudios Constitucionales, Año 5 N 1, 2007, p. 120.

${ }^{15}$ Rodríguez, J., "Los tratados internacionales y los controles de constitucionalidad”, en Revista Española de Derecho Administrativo, 30, 1981, p. 476. 
cuestión que no ocurrirá si el Presidente de la República lo aprobó en el ejercicio de su potestad reglamentaria autónoma.

Lo anterior se confirma por lo dispuesto en el artículo 93 inciso segundo de la Constitución que establece - para el control del artículo $93 \mathrm{~N}^{\circ} 1$ - que la Cámara de origen enviará al Tribunal Constitucional el proyecto respectivo dentro de los cinco días siguientes a aquel en que quede "totalmente tramitado por el Congreso"16; y en el inciso cuarto que dispone -para el control del artículo $93 \mathrm{~N}^{\circ} 3$ - que el Tribunal solo podrá conocer de la materia a requerimiento del Presidente de la República, de cualquiera de las Cámaras o de una cuarta parte de sus miembros en ejercicio, a partir de la remisión de la comunicación que informa "la aprobación del tratado por el Congreso Nacional" y, en caso alguno, después de quinto día del despacho de la señalada comunicación ${ }^{17}$.

Revisada la normativa constitucional y legal complementaria corresponde preguntarse: ¿Se encuentra facultado el Tribunal Constitucional para ejercer el control previo de constitucionalidad cuando el Presidente de la República califica que las normas de un tratado no versan sobre materias propias de ley, tratando sobre las mismas, y aprueba un tratado en el ejercicio de su potestad reglamentaria? La respuesta negativa se impone, ya que no está prevista constitucionalmente la oportunidad para que el Tribunal Constitucional conozca de este vicio de constitucionalidad formal, de modo obligatorio o facultativo, toda vez que su intervención requiere que el tratado haya sido sometido a la aprobación del Congreso Nacional, circunstancia que justamente no se produce.

\section{Facultades de la Contraloría General de la República para EJERCER CONTROL PREVIO DE JURIDICIDAD DE UN TRATADO APROBADO por el Presidente de la República EN EL EJERCiCio de su POTESTAd REGLAMENTARIA AUTÓNOMA}

La Contraloría General de la República ha ejercido el control de juridicidad de los decretos supremos que aprueban los acuerdos o tratados internacionales dictados por el Presidente de la República en el ejercicio de la potestad reglamentaria. En este control de juridicidad-constitucionalidad el órgano contralor ha verificado el cumplimiento de los supuestos del artículo $54 \mathrm{~N}^{\circ} 1$ inciso cuarto constitucional, representando aquellos

\footnotetext{
${ }^{16}$ A su vez la Ley Orgánica del Tribunal Constitucional expresa en su artículo 48 inciso segundo que el plazo de cinco días a que se refiere el inciso segundo del artículo 93 de la Constitución se contará desde que quede totalmente tramitado por el Congreso el tratado respectivo, lo que certificará el Secretario de la Cámara de origen. Además señala que si durante la discusión del tratado se hubiere suscitado cuestión de constitucionalidad de uno o más de sus preceptos, deberán enviarse al Tribunal, además, las actas de las sesiones, de sala o comisión, o el oficio del Presidente de la República, en su caso, donde conste la cuestión de constitucionalidad debatida o representada.

${ }^{17}$ Lo señalado se corrobora por el artículo 62 de la Ley $\mathrm{N}^{\circ} 17.997$, Ley Orgánica del Tribunal Constitucional, que dispone que no podrán admitirse requerimientos contra tratados si estos se presentan después del quinto día siguiente a la remisión de la comunicación que informa la aprobación del tratado por el Congreso Nacional.
} 
decretos supremos que aprueban tratados internacionales, cuando estima que versan sobre materias propias del dominio legal y no fueron sometidos por el Presidente al trámite de aprobación del Congreso Nacional.

La Contraloría ha asumido que su atribución para ejercer el control de juridicidad de la potestad reglamentaria surge del artículo 99 de la Constitución que expresa: "En el ejercicio de la función de control de legalidad, el Contralor General tomará razón de los decretos y resoluciones que, en conformidad a la ley, deben tramitarse por la Contraloría o representará la ilegalidad de que puedan adolecer (...)”. Por su parte, esta atribución ha sido pormenorizada en el artículo 10.4.1 de la Resolución 1600 de 2008 que "fija normas sobre exención del trámite de toma de razón” y establece que se encuentran afectos a toma de razón "los tratados internacionales y medidas que incidan en su vigencia; y acuerdos con entidades extranjeras u organismos internacionales incluidas las transacciones que ante ellos celebren”.

Algunos ejemplos de lo afirmado lo constituyen los dictámenes números 56.937 de 20 de noviembre de 2006, 27.810 de 28 de mayo de 2009, 13.578 de 15 de marzo de 2010, 17.885 de 6 de abril de 2010, 31.685 de 14 de junio de 2010, entre otros.

El primer dictamen mencionado devolvió sin tramitar el decreto promulgatorio No 288/2006, del Ministerio de Relaciones Exteriores, mediante el cual se promulgó el Acuerdo de Coproducción Cinematográfica y su Anexo, con el gobierno de Italia, del 6/10/2004, basado en el siguiente argumento: "La Contraloría General ha debido abstenerse de dar curso al decreto (...) por cuanto dicho tratado debe ser aprobado por el Congreso Nacional antes de su ratificación, de acuerdo con lo dispuesto en el artículo $54, \mathrm{~N}^{\circ} 1$, inciso primero, de la Constitución Política. Cabe agregar que el referido acuerdo internacional no se encuentra comprendido dentro de la excepción prevista en el inciso cuarto del citado $\mathrm{N}^{\circ} 1$, en cuanto dispone que "no requerirán de aprobación del Congreso los tratados celebrados por el Presidente de la República en el ejercicio de su potestad reglamentaria" (...); por cuanto en el mismo acuerdo se tratan materias que exceden dicha potestad $(. . .)^{18}$.

En el segundo caso, la Contraloría General se negó a dar curso al decreto No 51 , de 2009, del Ministerio de Relaciones Exteriores, mediante el cual se promulgó el memorándum de entendimiento entre el gobierno de la República de Chile y el gobierno del Reino de Dinamarca, en materia de programa de vacaciones con permiso de trabajo, por cuanto dicho tratado debía ser aprobado por el Congreso Nacional antes de su ratificación, de acuerdo con lo dispuesto en el artículo 54, $\mathrm{N}^{\circ} 1$, inciso primero, de la Constitución Política. El dictamen en comento aseveró que: "De esta manera, se puede apreciar que la ley ha fijado el plazo máximo de permanencia de los turistas en el territorio nacional, por lo que cualquier modificación en esta materia debe ser dispuesta por una norma de ese carácter, y no en ejercicio de la potestad reglamentaria, de modo que el convenio internacional en examen debe ser sometido a la aprobación del Congreso" ${ }^{19}$.

\footnotetext{
${ }^{18}$ Contraloría General de la República. Dictamen N 56.937 .20 de noviembre de 2006.

${ }^{19}$ Contraloría General de la República. Dictamen N ${ }^{\circ} 27.810 .28$ de mayo de 2009.
} 
En otro caso, y con mayor rotundidad, la Contraloría General se negó a dar curso al decreto $N^{\circ} 17$, de 2010, del Ministerio de Relaciones Exteriores, que promulgó el Acuerdo entre Chile y España sobre Participación en las Elecciones Municipales de los Nacionales de cada País Residentes en el Territorio del Otro, por cuanto dicho tratado debía ser aprobado por el Congreso Nacional antes de su ratificación, de acuerdo con lo dispuesto en el artículo 54, $\mathrm{N}^{\circ}$ 1, inciso primero, de la Constitución Política. El órgano contralor estimó que el referido acuerdo internacional no se encuentra comprendido dentro de la excepción prevista en el inciso cuarto del citado $\mathrm{N}^{\circ} 1$, en cuanto dispone que "no requerirán de aprobación del Congreso los tratados celebrados por el Presidente de la República en el ejercicio de su potestad reglamentaria”, toda vez que en el citado instrumento se tratan materias que exceden dicha potestad. A mayor abundamiento explicó que "corresponde a la ley, determinar la forma en que los extranjeros ejercen el derecho a sufragio, por lo que las disposiciones que versen sobre esta materia y sus modificaciones deben ser establecidas por una norma de ese carácter y no en ejercicio de la potestad reglamentaria, de modo que el convenio internacional en examen debe ser sometido a la aprobación del Congreso" ${ }^{20}$.

Asimismo, en 2010, el órgano contralor se abstuvo de dar curso al decreto $\mathrm{N}^{\circ} 184$, de 2009, del Ministerio de Relaciones Exteriores, mediante el cual se promulga el Acuerdo sobre Residencia para Nacionales de los Estados Partes del MERCOSUR, Bolivia y Chile, por cuanto dicho tratado debía ser aprobado por el Congreso Nacional antes de su ratificación (...) Finalizó el dictamen afirmando que: "En consecuencia, dado que el objeto del acuerdo que se analiza, y todo el contenido del mismo dicen relación con la residencia en el país de extranjeros, materia que es propia de ley, cualquier modificación que se desee introducir en este campo debe necesariamente ser dispuesta por una norma de ese carácter, y no en ejercicio de la potestad reglamentaria, de modo que el convenio internacional en examen debe ser sometido a la aprobación del Congreso, criterio que guarda armonía con lo expresado en el dictamen No 27.810, de 2009, de esta Contraloría General. No 13.578. 15 de marzo de 2010”. Contraloría General de la República ${ }^{21}$.

Finalmente, también en 2010, la Contraloría General se abstuvo de dar curso al decreto $\mathrm{N}^{\circ}$ 105, de 2010, del Ministerio de Relaciones Exteriores, mediante el cual se promulgó el Acuerdo para el Establecimiento de Centros Culturales entre la República de Chile y la República Argentina, en atención a que "dicho tratado debe ser aprobado por el Congreso Nacional antes de su ratificación, conforme con lo dispuesto en el artículo 54, $\mathrm{N}^{\circ} 1$ ), inciso primero, de la Constitución Política”. El argumento brindado por el órgano contralor es que: "el referido acuerdo internacional no se encuentra comprendido dentro de la excepción prevista en el inciso cuarto del citado $\mathrm{N}^{\circ} 1$ ) (...)”, toda vez que la materia regulada por el acuerdo es propia del dominio legal de iniciativa exclusiva del Presidente de la República, de conformidad con el No 2 del inciso cuarto del artículo 65 de la Carta Fundamental, esto es "crear nuevos servicios públicos o empleos rentados, sean

\footnotetext{
${ }^{20}$ Contraloría General de la República. Dictamen No 17.885 .6 de abril de 2010.

${ }^{21}$ Dictamen $\mathrm{N}^{\mathrm{o}}$ 13.578. 15 de marzo de 2010.
} 
fiscales, semifiscales, autónomos o de las empresas del Estado; suprimirlos y determinar sus funciones o atribuciones". Ratificó lo afirmado expresando: "En este contexto, dado que el objeto del acuerdo que se analiza, y todo el contenido del mismo, dice relación con el establecimiento de un organismo que reviste las características de un servicio público, la creación del referido centro cultural de Chile en Argentina constituye una materia que es propia de ley, por lo que su autorización debe necesariamente ser dispuesta por una norma de ese carácter, de modo que el convenio internacional en examen debe ser sometido a la aprobación del Congreso Nacional" 22 .

En los ejemplos referidos, la Contraloría razonó respecto de su competencia para verificar la constitucionalidad de los procedimientos de aprobación de los tratados o acuerdos, a propósito de su facultad para controlar la legalidad de los decretos supremos promulgatorios de los mismos. En tal contexto, se negó a tomar razón sobre la base de los siguientes razonamientos: a) Si el tratado versa sobre materia de ley, este no se enmarca en la excepción del artículo 54 N 1 inciso cuarto de la Constitución, es decir, no es un tratado que por razón de la materia pueda ser celebrado por el Presidente de la República en ejercicio de su potestad reglamentaria autónoma; b) Que el correspondiente tratado debe ser aprobado por el Congreso Nacional antes de la ratificación; c) Como no se cumplió con el trámite de aprobación por el Congreso no corresponde tomar razón del decreto promulgatorio del tratado.

\section{LA PROCEDENCIA DEL CONTROL REPRESIVO DE CONSTITUCIONALIDAD} DE LOS DECRETOS SUPREMOS QUE APRUEBAN TRATADOS

Finalmente, intentaré abordar la siguiente interrogante ¿Está facultado el Tribunal Constitucional para ejercer el control represivo de constitucionalidad del decreto supremo aprobatorio del tratado de conformidad con el artículo $93 \mathrm{~N}^{\circ} 16$ constitucional? Procede recordar que el artículo 93 de la Constitución señala las atribuciones del Tribunal Constitucional, siendo la última, $\mathrm{N}^{\circ} 16$, de este tenor: "Resolver sobre la constitucionalidad de los decretos supremos, cualquiera sea el vicio invocado, incluyendo aquellos que fueren dictados en el ejercicio de la potestad reglamentaria autónoma del Presidente de la República cuando se refieran a materias que pudieran estar reservadas a la ley por mandato del artículo 63”.

El Tribunal Constitucional tuvo la oportunidad de expedirse en 1999 acerca de un requerimiento formulado por distintos diputados que impugnaron la constitucionalidad del decreto supremo $\mathrm{N}^{\circ} 1.412$ del Ministerio de Relaciones Exteriores, por el cual se promulgó el Décimo Protocolo Adicional y su anexo al acuerdo de complementación económica con Bolivia $\mathrm{N}^{0}$ 22. Los requirentes estimaron que tal decreto supremo era inconstitucional al tratar materia legal -modificación de tributos correspondientes al arancel aduanero- y se promulgó omitiéndose la formalidad habilitante de la autorización

\footnotetext{
${ }^{22}$ Contraloría General de la República. Dictamen No 31.685 de 2010.14 de junio de 2010.
} 
del Congreso Nacional, transgrediendo el artículo $50 \mathrm{~N}^{\circ} 1$ de la época -hoy $54 \mathrm{~N}^{\circ} 1-$ además de los artículos $6^{\circ}$ y $7^{\circ}$ de la Constitución, toda vez que el Presidente de la República "no sometió su acción a la Carta Fundamental, actuó fuera de su competencia y se atribuyó derechos que no le fueron expresamente conferidos por la Constitución” ${ }^{23}$.

El Tribunal Constitucional estimó que el decreto supremo en cuestión era constitucional al haberse dictado en el ejercicio de la potestad reglamentaria de ejecución del Presidente de la República, en tanto el Protocolo Adicional se limitó a desarrollar el Tratado Marco de Montevideo (ALADI), no siendo por tal razón necesario la aprobación del Congreso Nacional ${ }^{24}$.

En lo que respecta al tema, y sin perjuicio que el Tribunal Constitucional estimó el caso como uno en que se ejerció válidamente la potestad reglamentaria de ejecución y no autónoma (objeto de este estudio), el órgano de justicia constitucional concluyó que el objeto del control es el decreto supremo promulgatorio del tratado y no el tratado mismo.

Así en el considerando 26 de la sentencia sostuvo: "Que un planteamiento de esa naturaleza resulta inadmisible, pues se aparta de la facultad que confiere el artículo $82, \mathrm{~N}^{\circ} 5^{\circ}$, de la Constitución Política, por cuanto por la sola impugnación del Decreto $\mathrm{N}^{\circ} 1.412$, y de la eventual inconstitucionalidad del Décimo Protocolo Adicional, llevaría a este Tribunal a emitir un pronunciamiento material implícito sobre la constitucionalidad del Tratado de Montevideo de 1980, incorporado al ordenamiento jurídico interno y con plena validez jurídica, pronunciamiento de carácter represivo que le está vedado, en razón de que dentro de las facultades que taxativamente le confiere la Carta Fundamental, en su artículo 82, en ninguna de ellas se le autoriza para emitir juicios o pronunciamientos sobre la constitucionalidad de una norma jurídica de esta naturaleza, en vigencia”.

De esta forma, el Tribunal Constitucional estableció el siguiente precedente: a) Procede controlar la constitucionalidad del decreto supremo promulgatorio del tratado, esto es un juicio sobre el procedimiento de celebración de este último; b) No procede pronunciarse sobre la constitucionalidad del tratado. Lo contrario implicaría controlar represivamente la constitucionalidad del tratado, asunto que le estaría vedado.

${ }^{23}$ Tribunal Constitucional. Rol No 282. 28 de enero de 1999.

${ }^{24} \mathrm{El}$ considerando $20^{\circ}$ de la sentencia expresó: "Que, en estas circunstancias, cabe concluir que el Decreto Supremo No 1.412, impugnado, y el Décimo Protocolo Adicional al Acuerdo de Complementación Económica con Bolivia $\mathrm{N}^{\circ} 22$, que ese decreto promulga, se enmarcan dentro de la Potestad Reglamentaria del Presidente de la República, y por cierto, el Décimo Protocolo Adicional en el ámbito de las amplias atribuciones que, como conductor superior de las relaciones internacionales, la Carta Fundamental confiere al Presidente de la República en su artículo 32, N 17 , en relación, en este caso, con lo que la Constitución establece en su artículo 50, $\mathrm{N}^{\circ} 1$ ), inciso segundo, que perentoriamente dispone, que las medidas que el Presidente de la República adopte o los acuerdos que celebre para el cumplimiento de un tratado en vigor, como acontece en la situación de autos, no requerirán nueva aprobación del Congreso, a menos que se trate de materias propias de ley, cuestión esta última que no concurre en la especie, de conformidad con lo concluido en los fundamentos anteriores". Tribunal Constitucional. Rol No 282. 28 de enero de 1999. 


\section{CONCLusiones}

La Constitución impone al Presidente de la República someter un tratado internacional a la aprobación del Congreso Nacional cuando el mismo versa sobre materias propias de ley. El no sometimiento de un acuerdo internacional, cuyas normas tratan materia legal, al control parlamentario importa una infracción constitucional o inconstitucionalidad de forma.

Si el tratado es ajeno a las materias comprendidas en la reserva legal, el Presidente podrá aprobarlo en el ejercicio de su potestad reglamentaria autónoma y no será obligatorio someterlo a la aprobación parlamentaria.

De esta forma, la Constitución relaciona los posibles contenidos del tratado con las materias del dominio legal, reiterando la distribución de materias reservadas a ley y a la potestad reglamentaria autónoma. Dispuesto así el diseño constitucional, la exclusión del control parlamentario, como fase de tramitación del tratado internacional, obedece más a una razón material que a la urgencia de la entrada en vigor o a la necesidad de una forma simplificada para su conclusión.

¿Qué sucede cuando el Presidente de la República estima que un tratado internacional no versa sobre materias propias de ley y lo aprueba en el ejercicio de su potestad reglamentaria autónoma, en circunstancias que el tratado sí regula materia legal? ¿Procede requerir el control previo de constitucionalidad al Tribunal Constitucional? No está prevista ni constitucional ni legalmente la oportunidad para que el Tribunal Constitucional conozca de la infracción constitucional que importa el no sometimiento de un tratado a la aprobación del Congreso cuando este versa sobre materia de ley, toda vez que la intervención del órgano de justicia constitucional requiere que el tratado haya sido sometido a dicho trámite de aprobación, circunstancia que no ocurre cuando fue aprobado por el Presidente de la República en el ejercicio de su potestad reglamentaria.

¿Es competente la Contraloría General de la República para detectar la infracción cuando ejerce el control previo de juridicidad del decreto supremo por el cual se aprobó el tratado? La jurisprudencia administrativa, emanada de la Contraloría General, ha cimentado su competencia para verificar la constitucionalidad del procedimiento de aprobación del tratado, a propósito de su facultad para controlar la legalidad del decreto supremo promulgatorio de aquel. En tal contexto, se ha negado a tomar razón cuando el tratado versa sobre materia de ley, es decir, no es un tratado que por razón de la materia pueda ser aprobado por el Presidente de la República en ejercicio de su potestad reglamentaria autónoma. A su vez, ha afirmado que en estos supuestos el tratado debe ser aprobado por el Congreso Nacional antes de la ratificación y que al no cumplir tal trámite no corresponde tomar razón del decreto supremo promulgatorio.

Finalmente, ¿podría un cuarto de los diputados en ejercicio requerir al Tribunal Constitucional para que ejerza un control represivo del decreto supremo aprobatorio del tratado de conformidad con el artículo $93 \mathrm{~N}^{\circ} 16$ ? El Tribunal Constitucional tuvo oportunidad de pronunciarse sobre la improcedencia del control represivo del tratado por esta vía, aun cuando reconoció la facultad para pronunciarse sobre el decreto supremo promulgatorio del tratado. De esta forma, al controlar la constitucionalidad del 
decreto supremo promulgatorio del tratado realizó en un juicio sobre el procedimiento de celebración del mismo, sin pronunciarse sobre el contenido del tratado. Lo contrario implicaría, a juicio del Tribunal Constitucional, controlar represivamente la constitucionalidad del tratado, asunto que a juicio de la sentencia de 1999 le está vedado.

\section{BiBLIOGRAFÍA}

Aldunate, E., "La posición de los tratados internacionales en el sistema de fuentes del ordenamiento jurídico chileno a la luz del derecho positivo", en Revista Ius et Praxis, Año 16, No 12, 2010, pp. 185- 201.

Benadava, S., Derecho Internacional Público, LexisNexis (8a edición), Santiago, 2004.

EsPaDA, M., "El control interno de los tratados internacionales", en Revista Española de Derecho Internacional, 1 y 3, 1980, pp. 9-32.

Cordero, E., "Las normas administrativas y el sistema de fuentes", en Revista de Derecho Universidad Católica del Norte, Año $17 \mathrm{~N}^{\circ} 1,2010$, pp. 21-50.

Correa, R., "Los acuerdos en forma simplificada en una Constitución democrática: comentario a fallo del Tribunal Constitucional", en Estudios Públicos, 75, 1999, pp. 67-105.

FERNÁNDEZ, M., "Visión prospectiva en relación con la regulación constitucional de los tratados internacionales", en Revista Ius et Praxis, 9 N 1, 2003, pp. 485-511.

García, A., "La reforma constitucional de 2005 en materia de Gobierno, con especial referencia a las atribuciones presidenciales", en Nogueira H. (coordinador), La Constitución reformada de 2005, Librotecnia, Santiago, 2005.

Henríquez, M., "Atribución exclusiva del Congreso: aprobación de tratados internacionales", en Revista de Derecho Público, 65, 2003, pp. 255-267.

Henríquez, M., "Improcedencia del control represivo de constitucionalidad de tratados internacionales", en Revista Estudios Constitucionales, Año 5 No 1, Talca, 2007, pp. 119-126.

Henríquez, M., "Los jueces y la resolución de antinomias desde la perspectiva de las fuentes del Derecho Constitucional chileno", en Revista Estudios Constitucionales, Año 11 No 1, 2013, pp. 459-476.

Henríquez, M., "Los tratados internacionales en la Constitución reformada", en Revista de Derecho Público, 69, 2007, pp. 313-323.

Huerta, C., Conflictos normativos, Instituto de Investigaciones Jurídicas UNAM, México, 2007.

Llanos, H., "Los tratados y la reforma constitucional", en Nogueira H. (coordinador), La Constitución reformada de 2005, Librotecnia, Santiago, 2005, pp. 345-379.

Llanos, H., "Vigencia de los tratados en Chile", en Revista Chilena de Derecho, No 4, 1977, pp. 198-195.

Nogueira, H., "Reforma constitucional de 2005 y control de constitucionalidad de tratados internacionales", en Revista Estudios Constitucionales, Año 5, 2007, pp. 59-88.

Pfeffer, E., "Constitución Política de la República y Tratados Internacionales", Revista Ius et Praxis, Vol. 2 No 2, 1997, pp. 63 y 72.

Rodríguez, Bárbara, Potestad reglamentaria del Presidente de la República en materia de tratados internacionales. Memoria para optar al grado de Licenciado en Ciencias Jurídicas y Sociales, Universidad de Chile, 2010.

Rodríguez, J., "Los tratados internacionales y los controles de constitucionalidad", en Revista Española de Derecho Administrativo, 30, 1981, pp. 471-504. 